\title{
Honoré de Balzac, Philarète Chasles, Charles Rabou, Contes bruns, par une tête à l'envers
}

\section{Valentina Ponzetto}

\section{Q OpenEdition}

1 Journals

\section{Edizione digitale}

URL: https://journals.openedition.org/studifrancesi/37917

DOI: 10.4000/studifrancesi.37917

ISSN: 2421-5856

\section{Editore}

Rosenberg \& Sellier

\section{Edizione cartacea}

Data di pubblicazione: 15 décembre 2004

Paginazione: 629

ISSN: 0039-2944

\section{Notizia bibliografica digitale}

Valentina Ponzetto, «Honoré de Balzac, Philarète Chasles, Charles Rabou, Contes bruns, par une tête à l'envers», Studi Francesi [Online], 144 (XLVIII | III) | 2004, online dal 30 novembre 2015, consultato il 08 mai 2021. URL: http://journals.openedition.org/studifrancesi/37917 ; DOI: https://doi.org/10.4000/ studifrancesi.37917

Questo documento è stato generato automaticamente il 8 mai 2021.

\section{(c)}

Studi Francesi è distribuita con Licenza Creative Commons Attribuzione - Non commerciale - Non opere derivate 4.0 Internazionale. 


\title{
Honoré de Balzac, Philarète Chasles, Charles Rabou, Contes bruns, par une tête à l'envers
}

\author{
Valentina Ponzetto
}

\section{NOTIZIA}

HONORÉ DE BALZAC, PHILARÈTE CHASLES, CHARLES RABOU, Contes bruns, par une tête à l'envers, édition de Marie-Christine NATTA, Jaignes, La Chasse au Snark,, 2002, pp. 327.

1 Fedele al suo proposito di ripresentare al pubblico opere minori, dimenticate o rare dell'Ottocento, La Chasse au Snark pubblica i Contes bruns di Balzac, Chasles e Rabou, raccolta di racconti di genere e tono assai vari, seppur con una buona parte di fantastico, apparsa nel 1832 sotto la doppia maschera dell'anonimato e dell'inquietante«tête à l'envers» e in seguito raramente riedita in maniera integrale e conforme all'originale. È invece proprio quest'ultima la scelta che ha fedelmente adottato Marie-Christine Natta per la presente edizione, limitandosi a modernizzare l'ortografia e a rettificare alcuni errori tipografici.

2 Nell'introduzione la studiosa traccia in primo luogo il ritratto dei tre autori, all'epoca giovani giornalisti ambiziosi, poi ripercorre la storia dei loro rapporti, e mette in luce le componenti della loro impresa editoriale. Questo era infatti innanzitutto il progetto dei Contes bruns: un'impresa editoriale concepita per fruttare in breve tempo parecchio denaro e successo letterario.

3 L'autrice analizza quindi tutti quegli elementi che sembravano assicurare l'uno e l'altro ad un autore di racconti intorno al 1830, tratteggiando al tempo stesso un più ampio quadro dell'orizzonte letterario dell'epoca: i princìpi della brevità e della varietà, ispiratori di un'innumerevole serie di raccolte spesso eterogenee; la voga del fantastico di stampo hoffmanniano; il gioco dell'anonimato, del resto presto svelato, per attirare 
la curiosità del pubblico; ed infine, in parte allo stesso scopo, il riferimento ad un colore.

4 Ma, avverte Natta, i Contes bruns testimoniano anche di una crisi. Crisi del genere fantastico, innanzitutto, ormai abusato nel 1832 e a cui infatti i nostri autori non dedicano che un terzo della raccolta, mantenendo per di più una certa ambiguità $\mathrm{e}$ distanza ironica, ma più ancora e più profondamente crisi della letteratura stessa $\mathrm{e}$ della società del tempo. Attraverso questi racconti, come mostra l'ultima parte dell'introduzione, traspaiono il malessere dell'artista che non trova più un posto nella società borghese, il pessimismo, la disillusione e l'inquietudine nei confronti di questa stessa società, il bisogno sempre crescente di distanziarsi da una narrativa esagerata $\mathrm{e}$ «frenetica» e di interrogarsi sul problema estetico del vero in letteratura. La risposta sarebbe nel realismo balzacchiano che al nero del romanzo gotico, straordinario e spettacolare oppone il bruno di soggetti toccanti o sublimi tratti dall'attualità sociale $\mathrm{e}$ politica e restituiti in modo da dare la perfetta illusione della massima naturalezza e semplicità del racconto.

5 In appendice ai testi sono riportati in versione integrale tutti i dieci articoli critici apparsi all'epoca della pubblicazione della raccolta, ciascuno accompagnato da un breve commento della curatrice. Chiude il volume una bibliografia, essenziale dal punto di vista della letteratura secondaria, ma estremamente precisa nel rendere conto della varia e complessa fortuna editoriale dei racconti, oggetto di pubblicazioni parziali soprattutto intese a scorporare, insieme o singolarmente, i due testi balzacchiani Une Conversation entre onze heures et minuit e Le Grand d'Espagne. 